\title{
Erratum to: Stefan Goltzberg: L'argumentation Juridique
}

Dalloz, Paris, 2013, 118 pp, ISBN: 978-2-247-12552-4

\section{Audrey Soussan}

Published online: 30 March 2014

(C) Springer Science+Business Media Dordrecht 2014

\section{Erratum to: Int J Semiot Law \\ DOI 10.1007/s11196-014-9376-7}

Dans la publication originale de cet article, l'auteur n'a pas cité le titre correct de la thèse de philosophie de Stefan Goltzberg.

A la dernière phrase du premier paragraphe, il ne faut pas lire «il a écrit une thèse de philosophie intitulé Théorie et histoire de la philosophie du droit, philosophie du droit de Chaïm Perelman, de Theodor Viehweg, de Roscoe Pound» mais bien «il a écrit une thèse de philosophie intitulée Théorie bidimensionnelle de l'argumentation. Définition, Présomption, Argument A fortiori».

The online version of the original article can be found under doi:10.1007/s11196-014-9376-7.

\footnotetext{
A. Soussan $(\square)$

Cedin, Université Paris Ouest Nanterre, Paris, France

e-mail: audrey.soussan@laposte.net
} 